Prismatika: Jurnal Pendidikan dan Riset Matematika Vol. 3 No. 1 (2020)

p-ISSN: 2654-6140, e-ISSN: 2656-4181

http://ejurnal.budiutomomalang.ac.id/index.php/prismatika

\title{
KEMAMPUAN SPASIAL PERCEPTION DALAM MENYELESAIKAN MASALAH GEOMETRI BERDASARKAN TEORI VAN HIELE DITINJAU DARI KEMAMPUAN MATEMATIKA
}

\author{
Amalia Mareta Pungkasari1, FX. Didik Purwosetiyono², \\ Agnita Siska Pramasdyahsari ${ }^{3}$ \\ Universitas PGRI Semarang1,2,3 \\ amaliamareta44@gmail.com ${ }^{1}$, didikpurwo@upgris.com², \\ agnitasiska@upgris.com ${ }^{3}$
}

\begin{abstract}
Abstrak
Kesulitan dalam belajar geometri berhubungan dengan kemampuan spasial. Kemampuan spasial yang baik akan membuat siswa mampu menyelesaikan masalah geometri. Teori belajar yang dapat membantu mengatasi kesulitan siswa belajar geometri adalah teori Van Hiele. Penelitian deskriptif kualitatif ini bertujuan mendeskripsikan kemampuan spasial perception dalam menyelesaikan masalah geometri berdasarkan teori Van Hiele ditinjau dari kemampuan matematika. Subjek dalam penelitian ini adalah tiga siswa SMP berkemampuan matematika tinggi, sedang dan rendah. Subjek diberi tes kemampuan spasial dan dilakukan wawancara dua kali. Triangulasi waktu dan subjek dilakukan untuk menguji kredibilitas data. Berdasarkan hasil analisis data siswa berkemampuan matematika tinggi, sedang dan rendah mampu mengamati benda dari perspektif yang berbeda. Subjek berkemampuan matematika sedang mampu mangamati benda dari perspektif yang berbeda. Namun, subjek berkemampuan matematika tinggi dan rendah kesulitan dalam mengamati benda dari persepektif yang berbeda.
\end{abstract}

Kata kunci: spasial perception, Van Hiele, kemampuan matematika

\begin{abstract}
Difficulties in learning geometry relate to spatial abilities. Students with good spatial skills will be able to solve geometric problems. In helping students overcome difficulties in learning geometry, they used the Van Hiele's learning theory. This qualitative descriptive study aimed to describe the spatial perception ability in solving geometric problems based on Van Hiele's theory in terms of mathematical ability. The subjects in this study were three junior high school students with high, medium, and low math abilities. Subjects were given a spatial ability test and an interview twice. The triangulation time and subject was carried out to test the credibility of data. Based on the results of data analysis, students with high, medium, and low math abilities were able to observe objects from different perspectives. Subjects with medium math abilities were able to observe the object from different perspectives. However,
\end{abstract}


Amalia Mareta Pungkasari, FX. Didik Purwosetiyono, Agnita Siska Pramasdyahsari Kemampuan Spasial Perception dalam Menyelesaikan Masalah Geometri Berdasarkan Teori Van Hiele Ditinjau dari Kemampuan Matematika

subjects with high and low math abilities have some difficulties in observing objects from different perspectives.

Keywords: spatial perception, Van Hiele, math ability

\section{PENDAHULUAN}

Geometri diberikan untuk siswa dari sekolah dasar sampai menengah atas, walaupun geometri telah diajarkan dari sekolah dasar, akan tetapi masih banyak siswa yang kesulitan ketika dihadapkan dengan materi geometri (Alimuddin, Musdalifah Asis, 2015). Geometri membutuhkan tingkat berpikir tinggi serta dapat memvisualisasikan gambar dengan baik, sehingga menyebabkan siswa kesulitan dalam belajar geometri (Yanty Putri Nasution, 2017). Strategi yang dapat membantu dalam mengatasi kesulitan siswa belajar geometri adalah dengan menggunakan level berpikir dalam teori belajar yang dikemukakan oleh Van Hiele (Musa \& Aditya, 2014).

Teori Van Hiele itu sendiri mempunyai 5 level yaitu level 0 (visualisasi), level 1 (analisis), level 2 (deduktif informal), level 3 (deduktif), serta level 4 (rigor) (Sulistiowati, Herman, \& Jupri, 2019). Dalam tingkatan level teori van hiele tersebut, setiap siswa mempunyai ketrampilan dasar dalam menyelesaikan masalah geometri yang berbeda-beda (Muhassanah, Sujadi, \& Riyadi, 2014). Teori Van Hiele merupakan salah satu teori yang cocok digunakan dalam geometri untuk menentukan strategi yang tepat agar siswa tidak hanya menerima pelajaran geometri sebagai hafalan (Musa \& Aditya, 2014). Semua siswa dalam belajar geometri akan melalui tahapan tersebut secara urut.

Salah satu materi geometri yang digunakan dalam penelitian ini adalah dimensi tiga, yaitu bentuk bangun ruang. Bangun ruang merupakan materi yang sesuai untuk memunculkan kemampuan spasial siswa, karena dengan objek tertentu akan melatih kemampuan imajinasi siswa (Asryana, Sanapiah, \& Kinasih, 2017). Materi ini dapat melatih sikap dan daya ingat siswa, serta keterampilan dalam menggambar bangun ruang. Kemudian siswa dapat mengenal bentuk dari beberapa bangun ruang serta dapat memanipulasi objek (Purwosetiyono, 2011).

Kemampuan spasial adalah kemampuan untuk memvisualisasikan gambar (Ma'Rifatin, Amin, \& Siswono, 2019). Kemampuan spasial ini meliputi dua aspek, yaitu orientasi spasial dan visualisasi spasial. Aspek tersebut di contohkan seperti keterampilan untuk membaca dan mempresentasikan gambar dari tiga dimesi ke dua dimensi dari berbagai arah (Ingri Y.M. Lalan, Rully CharitasIndra Prahmana, 2017). Setiap siswa mempunyai kemampuan spasial yang berbeda-beda (Alimuddin, Musdalifah Asis, 2015). Kemampuan spasial yang baik akan membuat siswa mampu 
Amalia Mareta Pungkasari, FX. Didik Purwosetiyono, Agnita Siska Pramasdyahsari Kemampuan Spasial Perception dalam Menyelesaikan Masalah Geometri Berdasarkan Teori Van Hiele Ditinjau dari Kemampuan Matematika

menyelesaikan hubungan serta perubahan bentuk bangun ruang geometri (Syahputra, 2013).

Kemampuan spasial merupakan kemampuan yang penting bagi siswa untuk mempelajari geometri (Guzel \& Sener, 2009). Kemampuan spasial merupakan kemampuan unuk memanipulasi, merotasi objek dan merupakan suatu kemampuan untuk dapat membayangkan objek dari perspektif yang berbeda (Febriana, 2015). Kemampuan spasial ini juga berkaitan dengan kemampuan matematika (Tosto et al., 2014). Penggunaan kemampuan spasial, seperti membuat bagan dan grafik dapat meningkatkan kemampuan matematika siswa (Farisdianto \& Budiarto, 2014). Kemampuan spasial yang digunakan dalam penelitian ini adalah suatu kemampuan untuk dapat memvisualisasikan gambar dan membayangkan sebuah objek ke dalam bentuk tiga dimensi dengan indikator spatial perception, vizualitation, mental rotation, spatial relation dan spatial orientation.

Kemampuan matematika dianggap mempengaruhi kemampuan spasial siswa dalam menyelesaikan masalah geometri (Ma'Rifatin et al., 2019). Kemampuan matematika ini dibedakan menjadi tiga yaitu kemampuan matematika tinggi, sedang dan rendah (Azustiani, 2017). Banyak siswa yang beranggapan bahwa matematika merupakan mata pelajaran yang sulit (Junsella Harmony, 2012). Kemampuan matematika siswa dinilai rendah, hal itu disebabkan karena kurang minatnya siswa dalam belajar matematika.

Penelitian yang berkaitan dengan kemampuan spasial dan masalah geometri berdasarkan teori van hiele telah banyak dilakukan. Beberapa penelitian yang telah dilakukan, menunjukan bahwa siswa baru sampai level 0-2 pada teori van hiele (Muhassanah et al., 2014). Penelitian yang dilakukan oleh (Febriana, 2015) mendapatkan hasil kemampuan spasial yang dimiliki siswa berkemampuan tinggi, sedang dan rendah berbeda-beda dalam menyelesaikan masalah geometri. Siswa yang berkemampuan tinggi dapat memanipulasi suatu objek dengan strategi yang lebih variatif. Siswa yang berkemampuan sedang dan rendah sulit membayangkan perubahan bentuk objek serta melihat kesamaan bentuk objek guna menyelesaikan masalah geometri.

Penelitian yang berkaitan dengan kemampuan spasial memang telah banyak dilakukan, akan tetapi penelitian yang saya teliti ini berbeda dengan penelitian sebelumnya. Perbedaannya yaitu pada penelitian ini menggabungkan antara kemampuan spasial serta masalah geometri yang berdasarkan teori van hiele dan ditinjau dengan kemampuan matematika siswa, sedangkan penelitian yang dilakukan oleh 1) (Muhassanah et al,, 2014) tentang analisis keterampilan geometri siswa dalam memecahkan masalah geometri berdasarkan tingkat teori van hiele mempunyai kelemahan 
Amalia Mareta Pungkasari, FX. Didik Purwosetiyono, Agnita Siska Pramasdyahsari Kemampuan Spasial Perception dalam Menyelesaikan Masalah Geometri Berdasarkan Teori Van Hiele Ditinjau dari Kemampuan Matematika

dalam setiap tingkatan teori van hiele siswa hanya bisa menentukan jenis bangun datar berdasarkan penampilan bentuknya, yang membedakan pada setiap tingkatannya hanya dalam keterampilan menggambar, logika serta terapan dan 2) (Febriana, 2015) tentang profil kemampuan spasial siswa SMP dalam menyelesaikan masalah geometri dimensi tiga ditinjau dari kemampuan matematika memiliki kelemahan dalam setiap tingkatan kemampuan matematika baik siswa yang mempunyai kemampuan matematika tinggi, sedang serta rendah masih kesulitan dalam mempresentasikan bayangan spasial dalam pikirannya sehingga perlu adanya penelitian tentang kemampuan spasial.

\section{METODE PENELITIAN}

Penelitian ini bertujuan untuk mendeskripsikan kemampuan spasial dalam menyelesaikan masalah geometri berdasarkan teori Van Hiele ditinjau dari kemampuan matematika. Berdasarkan tujuannya, penelitian ini merupakan penelitian deskriptif kualitatif. Pengumpulan data ini telah dilaksanakan pada bulan Juli 2020. Dengan pengambilan data tes kemampuan matematika pada tanggal 21 Juli 2020, pengambilan tes kemampuan spasial pertama pada tanggal 21 Juli 2020, dan pengambilan tes kemampuan spasial kedua pada tanggal 25 Juli 2020. Penelitian ini telah dilaksanakan di kelas IX SMP IT At Taufiiqiyyah Brabo, Grobogan. Subjek dalam penelitian ini adalah tiga orang siswa kelas IX yang sudah diberi tes kemampuan matematika yang masing-masing memiliki kemampuan matematika tinggi, sedang dan rendah. Pengelompokan siswa dalam tiga kelompok berdasarkan tes kemampuan matematika dengan kriteria penilaian yaitu $75 \leq$ nilai tes $\leq 100$ siswa tersebut memiliki kemampuan matematika tinggi. Kemampuan matematika sedang diperoleh oleh siswa dengan nilai $60 \leq$ nilai tes $<75$ dan kemampuan matematika rendah diperoleh oleh siswa dari nilai $0 \leq$ nilai tes $<60$ (Febriana, 2015). Instrumen dalam penelitian ini adalah tes kemampuan matematika, tes kemampuan spasial dan pedoman wawancara. Berikut merupakan contoh soal tes kemampuan spasial perception.

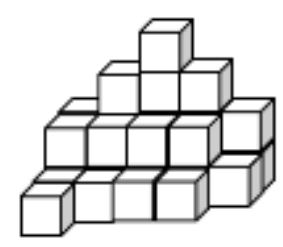

Gambar 1. Contoh Soal Spasial Perception 
Amalia Mareta Pungkasari, FX. Didik Purwosetiyono, Agnita Siska Pramasdyahsari Kemampuan Spasial Perception dalam Menyelesaikan Masalah Geometri Berdasarkan Teori Van Hiele Ditinjau dari Kemampuan Matematika

Tes kemampuan matematika digunakan untuk menentukan subjek penelitian yaitu siswa berkemampuan matematika tinggi, sedang dan rendah. Kemudian subjek penelitian diberikan tes kemampuan spasial sebanyak dua kali untuk mendapatkan data penelitian yang valid. Hasil tes kemampuan spasial dianalisis untuk menyusun kemampuan spasial dalam menyelesaikan masalah geometri berdasarkan teori Van Hiele ditinjau dari kemampuan matematika.

\section{HASIL DAN PEMBAHASAN}

Berikut merupakan hasil pengambilan data pertama dan kedua pada tanggal 21 Juli 2020 dan 25 Juli 2020 siswa berkemampuan matematika tinggi (ST), sedang (SS), dan rendah (SR).

1. Hasil Subjek ST

Berikut hasil tes kemampuan spasial siswa berkemampuan matematika tinggi (ST).

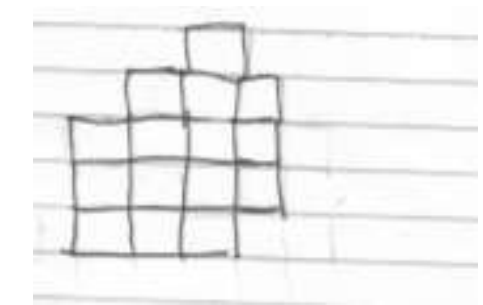

Gambar 2. Jawaban Subjek ST Tes I Kemampuan Spasial

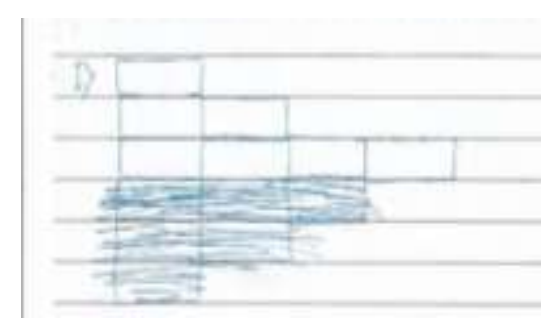

Gambar 3. Jawaban Subjek ST Tes II Kemampuan Spasial

Berdasarkan hasil tes di atas, kedua tes konsisten dalam mengamati bangun ruang dari atas. Subjek ST menggambarkan tumpukan kardus TV (kubus) tersebut menjadi persegi dan tumpukan kardus kulkas (balok) menjadi persegi panjang. Berikut merupakan tahapan Van Hiele yang telah subjek ST dapatkan. 
Amalia Mareta Pungkasari, FX. Didik Purwosetiyono, Agnita Siska Pramasdyahsari Kemampuan Spasial Perception dalam Menyelesaikan Masalah Geometri Berdasarkan Teori Van Hiele Ditinjau dari Kemampuan Matematika

Tabel 2. Tingkatan Van Hiele subjek ST

\begin{tabular}{|c|c|}
\hline Indikator Van Hiele & Tingkatan Van Hiele subjek ST \\
\hline $\begin{array}{l}\text { Level } 1 \text { (visual): ditandai dengan } \\
\text { persepsi siswa tentang angka } \\
\text { geometri. }\end{array}$ & $\begin{array}{l}\text { Subjek ST dapat menggambar } \\
\text { bentuk tumpukan kardus jika } \\
\text { dilihat dari atas. }\end{array}$ \\
\hline $\begin{array}{l}\text { Level } 2 \text { (analisis): siswa dapat } \\
\text { melihat sifat geometri serta } \\
\text { dapat menganalisis angka dan } \\
\text { mengenalinya berdasarkan sifat- } \\
\text { sifatnya. }\end{array}$ & $\begin{array}{l}\text { Subjek ST dapat menggambar } \\
\text { bentuk tumpukan kardus dari } \\
\text { atas akan tetapi tidak mengenali } \\
\text { berdasarkan sifat-sifatnya. }\end{array}$ \\
\hline $\begin{array}{l}\text { Level } 3 \text { (abstraksi): siswa telah } \\
\text { dapat membangun hubungan } \\
\text { diantara sifat-sifat geometri. }\end{array}$ & $\begin{array}{l}\text { Subjek ST dapat menggambar } \\
\text { bentuk tumpukan kardus, tetapi } \\
\text { tidak mengetahui hubungan } \\
\text { antara kubus serta balok dengan } \\
\text { persegi dan persegi panjang. }\end{array}$ \\
\hline $\begin{array}{l}\text { Level } 4 \text { (deduksi): siswa } \\
\text { mengatahui cara membangun } \\
\text { dan mengembangkan geometri. }\end{array}$ & $\begin{array}{l}\text { Subjek ST dapat menggambar } \\
\text { bentuk tumpukan kardus dari } \\
\text { atas, tetapi tidak dapat } \\
\text { mengembangkan hubungan } \\
\text { antara persegi dan persegi } \\
\text { panjang dengan kubus serta } \\
\text { balok. }\end{array}$ \\
\hline $\begin{array}{l}\text { Level } 5 \text { (rigor): siswa dapat } \\
\text { memahami sifat geometri serta } \\
\text { dapat sifat deduktif. }\end{array}$ & $\begin{array}{l}\text { Subjek ST dapat menggambar } \\
\text { bentuk tumpukan kardus dari } \\
\text { atas akan tetapi tidak mengenali } \\
\text { sifat-sifatnya serta tidak dapat } \\
\text { mengembangkan hubungan } \\
\text { antara persegi dan persegi } \\
\text { panjang dengan kubus serta } \\
\text { balok. }\end{array}$ \\
\hline
\end{tabular}

Berdasarkan tabel di atas, subjek ST berada pada tingkatan Van Hiele level 2 yaitu Subjek ST dapat menggambar bentuk tumpukan kardus dari atas akan tetapi tidak mengenali berdasarkan sifat-sifatnya.

2. Hasil subjek SS

Berikut hasil tes kemampuan spasial siswa berkemampuan matematika sedang (SS).

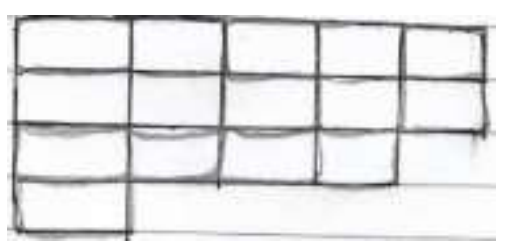

Gambar 4. Jawaban subjek SS Tes I Kemampuan Spasial 


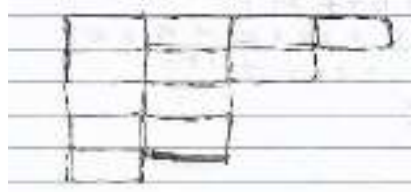

\section{Gambar 5. Jawaban Subjek SS Tes II Kemampuan Spasial}

Berdasarkan hasil kedua tes di atas, terdapat kekonsistenan dalam mengamati bangun ruang dari atas. Subjek SS menggambarkan tumpukkan kardus TV (kubus) tersebut menjadi persegi dan tumpukkan kardus kulkas (balok) menjadi persegi panjang. Berikut merupakan tahapan Van Hiele yang telah subjek SS dapatkan.

\section{Tabel 4. Tingkatan Van Hiele Subjek SS}

\begin{tabular}{|c|c|}
\hline Indikator Van Hiele & Tingkatan Van Hiele subjek SS \\
\hline $\begin{array}{l}\text { Level } 1 \text { (visual): ditandai dengan } \\
\text { persepsi siswa tentang angka } \\
\text { geometri. }\end{array}$ & $\begin{array}{l}\text { Subjek SS dapat menggambar } \\
\text { bentuk tumpukan kardus jika } \\
\text { dilihat dari atas. }\end{array}$ \\
\hline $\begin{array}{l}\text { Level } 2 \text { (analisis): siswa dapat } \\
\text { melihat sifat geometri serta } \\
\text { dapat menganalisis angka dan } \\
\text { mengenalinya berdasarkan sifat- } \\
\text { sifatnya. }\end{array}$ & $\begin{array}{l}\text { Subjek SS dapat menggambar } \\
\text { bentuk tumpukan kardus dari } \\
\text { atas dan dapat mengenali } \\
\text { berdasarkan sifat-sifatnya. }\end{array}$ \\
\hline $\begin{array}{l}\text { Level } 3 \text { (abstraksi): siswa telah } \\
\text { dapat membangun hubungan } \\
\text { diantara sifat-sifat geometri. }\end{array}$ & $\begin{array}{l}\text { Subjek SS dapat menggambar } \\
\text { bentuk tumpukan kardus dan } \\
\text { dapat mengetahui hubungan } \\
\text { antara kubus serta balok dengan } \\
\text { persegi dan persegi panjang. }\end{array}$ \\
\hline $\begin{array}{l}\text { Level } 4 \quad \text { (deduksi): siswa } \\
\text { mengatahui cara membangun } \\
\text { dan mengembangkan geometri. }\end{array}$ & $\begin{array}{l}\text { Subjek SS dapat menggambar } \\
\text { bentuk tumpukan kardus dari } \\
\text { atas dan dapat mengembangkan } \\
\text { hubungan antara persegi dan } \\
\text { persegi panjang dengan kubus } \\
\text { serta balok. }\end{array}$ \\
\hline $\begin{array}{l}\text { Level } 5 \text { (rigor): siswa dapat } \\
\text { memahami sifat geometri serta } \\
\text { dapat sifat deduktif. }\end{array}$ & $\begin{array}{l}\text { Subjek SS dapat menggambar } \\
\text { bentuk tumpukan kardus dari } \\
\text { atas dan dapat mengenali sifat- } \\
\text { sifatnya serta } \\
\text { mengembangkan dapat } \\
\text { antara persegi dan persegi } \\
\text { panjang dengan kubus serta } \\
\text { balok. }\end{array}$ \\
\hline
\end{tabular}

Berdasarkan tabel di atas, subjek SS berada pada tingkatan Van Hiele level 5 yaitu Subjek SS dapat menggambar bentuk tumpukan kardus dari 
Amalia Mareta Pungkasari, FX. Didik Purwosetiyono, Agnita Siska Pramasdyahsari Kemampuan Spasial Perception dalam Menyelesaikan Masalah Geometri Berdasarkan Teori Van Hiele Ditinjau dari Kemampuan Matematika

atas dan dapat mengenali sifat-sifatnya serta dapat mengembangkan hubungan antara persegi dan persegi panjang dengan kubus serta balok.

3. Hasil subjek SR

Berikut Hasil tes kemampuan spasial siswa berkemampuan matematika rendah (SR).

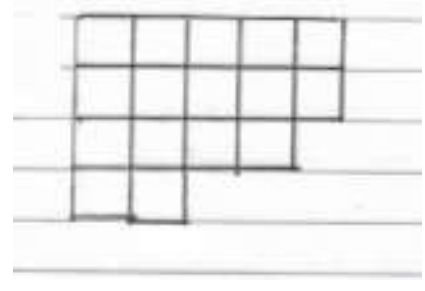

Gambar 6. Jawaban Subjek SR Tes I Kemampuan Spasial

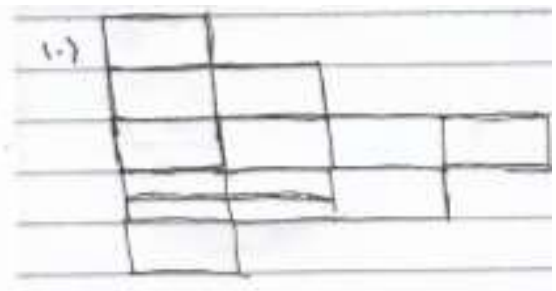

Gambar 7. Jawaban Subjek SR Tes II Kemampuan Spasial

Berdasarkan hasil kedua tes di atas, terdapat kekonsistenan dalam mengamati bangun ruang dari atas. Subjek SR menggambarkan tumpukkan kardus TV (kubus) tersebut menjadi persegi dan tumpukkan kardus kulkas (balok) menjadi persegi panjang. Berikut merupakan tahapan Van Hiele yang telah subjek SR dapatkan.

Tabel 6 Tingkatan Van Hiele Subjek SR

\begin{tabular}{|c|c|}
\hline Indikator Van Hiele & Tingkatan Van Hiele subjek SR \\
\hline $\begin{array}{l}\text { Level } 1 \text { (visual) : yang ditandai } \\
\text { dengan persepsi siswa tentang } \\
\text { angka geometri. }\end{array}$ & $\begin{array}{l}\text { Subjek SR dapat menggambar } \\
\text { bentuk tumpukan kardus jika } \\
\text { dilihat dari atas. }\end{array}$ \\
\hline $\begin{array}{l}\text { Level } 2 \text { (analisis) yang membuat } \\
\text { siswa dapat melihat sifat } \\
\text { geometri serta dapat } \\
\text { menganalisis angka dan } \\
\text { mengenalinya berdasarkan sifat- } \\
\text { sifatnya. }\end{array}$ & $\begin{array}{l}\text { Subjek SR dapat menggambar } \\
\text { bentuk tumpukan kardus dari } \\
\text { atas, tetapi tidak dapat mengenali } \\
\text { berdasarkan sifat-sifatnya. }\end{array}$ \\
\hline $\begin{array}{l}\text { Level } 3 \text { (abstraksi) yang siswa } \\
\text { telah dapat membangun } \\
\text { hubungan diantara sifat-sifat } \\
\text { geometri. }\end{array}$ & $\begin{array}{l}\text { Subjek SR dapat menggambar } \\
\text { bentuk tumpukan kardus, tetapi } \\
\text { tidak dapat mengetahui } \\
\text { hubungan antara kubus serta } \\
\text { balok dengan persegi dan persegi } \\
\text { panjang. }\end{array}$ \\
\hline
\end{tabular}


Amalia Mareta Pungkasari, FX. Didik Purwosetiyono, Agnita Siska Pramasdyahsari Kemampuan Spasial Perception dalam Menyelesaikan Masalah Geometri Berdasarkan Teori Van Hiele Ditinjau dari Kemampuan Matematika

\begin{tabular}{|c|c|}
\hline Indikator Van Hiele & Tingkatan Van Hiele subjek SR \\
\hline $\begin{array}{l}\text { Level } 4 \text { (deduksi) yang siswa } \\
\text { mengatahui cara membangun } \\
\text { dan mengembangkan geometri. }\end{array}$ & $\begin{array}{l}\text { Subjek SR dapat menggambar } \\
\text { bentuk tumpukan kardus dari } \\
\text { atas, tetapi tidak dapat } \\
\text { mengembangkan } \\
\begin{array}{l}\text { 2 hubungan } \\
\text { antara persegi }\end{array} \text { dan persegi } \\
\text { panjang dengan kubus serta } \\
\text { balok. }\end{array}$ \\
\hline $\begin{array}{l}\text { Level } 5 \text { (rigor) yang siswa dapat } \\
\text { memahami sifat geometri serta } \\
\text { dapat sifat deduktif. }\end{array}$ & $\begin{array}{l}\text { Subjek SR dapat menggambar } \\
\text { bentuk tumpukan kardus dari } \\
\text { atas, tetapi tidak dapat mengenali } \\
\text { sifat-sifatnya serta tidak dapat } \\
\text { mengembangkan } \\
\text { antara persegi dan persegi } \\
\text { panjang dengan kubus serta } \\
\text { balok. }\end{array}$ \\
\hline
\end{tabular}

Berdasarkan tabel di atas, subjek SR berada pada tingkatan Van Hiele level 2 yaitu Subjek SR dapat menggambar bentuk tumpukan kardus dari atas akan tetapi tidak dapat mengenali berdasarkan sifat-sifatnya.

Berikut merupakan pembahasan kemampuan spasial perception siswa dengan kemampuan matematika tinggi, sedang dan rendah dalam menyelesaikan masalah geomteri berdasarkan teori Van Hiele.

1. Kemampuan Spasial Perception Siswa dengan Kemampuan Matematika Tinggi (Subjek ST) dalam Menyelesaikan Masalah Geometri Berdasarkan Teori Van Hiele

Subjek ST dalam menyelesaikan soal kemampuan spasial pada indikator spatial perception, pada level 1 (visual) mampu menggambar benda tersebut jika dilihat dari atas. Pada level 2 (analisis) subjek ST dapat menggambar benda tersebut jika dilihat dari atas, tetapi tidak dapat mengenali berdasarkan sifat-sifatnya. Pada level 3 (abstraksi) subjek ST mampu menggambar bangun tersebut jika dilihat dari atas, tetapi tidak dapat mengetahui hubungan bangun ruang dengan bangun datar. Pada level 4 (deduksi) subjek ST mampu menggambar bangun tersebut jika dilihat dari atas, tetapi tidak dapat mengembangkan hubungan bangun ruang dengan bangun datar. Pada level 5 (rigor) subjek ST mampu menggambar bangun tersebut dari atas, tetapi tidak dapat mengenali berdasarkan sifat-sifatnya serta tidak dapat mengetahui dan mengembangkan hubungan antara bangun ruang dengan bangun datar. Sehingga dapat disimpulkan bahwa subjek ST belum optimal dalam spatial perception. Dalam penelitian sebelumnya (Febriana, 2015) siswa berkemampuan matematika tinggi kesulitan dalam mempresentasikan atau membayangkan bentuk dari persepektif yang berbeda. 
Amalia Mareta Pungkasari, FX. Didik Purwosetiyono, Agnita Siska Pramasdyahsari Kemampuan Spasial Perception dalam Menyelesaikan Masalah Geometri Berdasarkan Teori Van Hiele Ditinjau dari Kemampuan Matematika

2. Kemampuan Spasial Perception Siswa dengan Kemampuan Matematika Sedang (Subjek SS) dalam Menyelesaikan Masalah Geometri Berdasarkan Teori Van Hiele

Subjek SS dalam menyelesaikan soal kemampuan spasial pada indikator spatial perception, pada level 1 (visual) mampu menggambar benda tersebut jika dilihat dari atas. Pada level 2 (analisis) subjek SS dapat menggambar benda tersebut jika dilihat dari atas dan dapat mengenali berdasarkan sifat-sifatnya. Pada level 3 (abstraksi) subjek SS mampu menggambar bangun tersebut jika dilihat dari atas dan dapat mengetahui hubungan bangun ruang dengan bangun datar. Pada level 4 (deduksi) subjek SS mampu menggambar bangun tersebut jika dilihat dari atas dan dapat mengembangkan hubungan bangun ruang dengan bangun datar. Pada level 5 (rigor) subjek SS mampu menggambar bangun tersebut dari atas dan dapat mengenali berdasarkan sifat-sifatnya serta dapat mengetahui dan mengembangkan hubungan antara bangun ruang dengan bangun datar. Sehingga dapat disimpulkan bahwa subjek SS optimal dalam spatial perception. Dalam penelitian (Febriana, 2015) siswa berkemampuan matematika sedang kesulitan dalam mempresentasikan atau membayangkan bentuk dari persepektif yang berbeda. Hasil dari penelitian yang dilakukan oleh (Febriana, 2015) berbeda dengan hasil penelitian ini.

3. Kemampuan Spasial Perception Siswa dengan Kemampuan Matematika Rendah (Subjek SR) dalam Menyelesaikan Masalah Geometri Berdasarkan Teori Van Hiele

Subjek SR dalam menyelesaikan soal kemampuan spasial pada indikator spatial perception, pada level 1 (visual) mampu menggambar benda tersebut jika dilihat dari atas. Pada level 2 (analisis) subjek SR dapat menggambar benda tersebut jika dilihat dari atas dan akan tetapi tidak dapat mengenali berdasarkan sifat-sifatnya. Pada level 3 (abstraksi) subjek SR mampu menggambar bangun tersebut jika dilihat dari atas, tetapi tidak dapat mengetahui hubungan bangun ruang dengan bangun datar. Pada level 4 (deduksi) subjek SR mampu menggambar bangun tersebut jika dilihat dari atas, tetapi tidak dapat mengembangkan hubungan bangun ruang dengan bangun datar. Pada level 5 (rigor) subjek SR mampu menggambar bangun tersebut dari atas akan tetapi tidak dapat mengenali berdasarkan sifat-sifatnya serta tidak dapat mengetahui dan mengembangkan hubungan antara bangun ruang dengan bangun datar. Sehingga dapat disimpulkan bahwa subjek SR belum optimal spatial perception, hal ini sejalan dengan penelitian (Febriana, 2015) siswa berkemampuan matematika rendah kesulitan dalam membayangkan bentuk objek dari perspektif berbeda. 
Amalia Mareta Pungkasari, FX. Didik Purwosetiyono, Agnita Siska Pramasdyahsari Kemampuan Spasial Perception dalam Menyelesaikan Masalah Geometri Berdasarkan Teori Van Hiele Ditinjau dari Kemampuan Matematika

\section{KESIMPULAN DAN SARAN}

Pada indikator spatial perception, subjek berkemampuan matematika tinggi berada pada level 2 yaitu tidak dapat mengenali berdasarkan sifatsifatnya. Selanjutnya, subjek berkemampuan matematika sedang berada pada level 5 yaitu dapat mengenali berdasarkan sifat-sifatnya dan dapat mengembangkan hubungan antara bangun ruang dengan bangun datar. Sedangkan, subjek berkemampuan matematika rendah berada pada level 2 yaitu tidak dapat mengenali berdasarkan sifat-sifatnya.

Berdasarkan simpulan dalam penelitian ini, peneliti memberikan saran sebagai berikut. (1) siswa mampu menjadikan penelitian ini sebagai motivasi dalam menyelesaikan masalah geometri dengan menggunakan teori Van Hiele untuk mengembangkan kemampuan spasialnya, (2) guru dapat memberikan latihan-latihan kepada siswa guna mengembangkan kemampuan spasial yang dimiliki, terutama pada kemampuan membayangkan atau melihat objek dari atas, dan (3) peneliti selanjutnya dapat memperhatikan kesesuaian indikator dengan soal yang akan digunakan agar benar-benar mengetahui kemampuan spasial siswa dalam menyelesaikan masalah geometri.

\section{DAFTAR RUJUKAN}

Alimuddin, Musdalifah Asis, N. A. (2015). Profil Kemampuan Spasial Dalam Menyelesaikan Masalah Geometri Siswa Yang Memiliki Kecerdasan Logis Matematis Tinggi Ditinjau Dari Perbedaan Gender. Jurnal Daya Matematis, 3(1), 78. https://doi.org/10.26858/jds.v3i1.1320

Asryana, A., Sanapiah, S., \& Kinasih, I. P. (2017). Pengembangan Media Pembelajaran Interaktif Menggunakan Geogebra Untuk Meningkatkan Kemampuan Spasial Siswa. Media Pendidikan Matematika, 5(2), 107. https://doi.org/10.33394/mpm.v5i2.1836

Azustiani, H. (2017). Kemampuan Spasial Siswa Smp Kelas VIII Ditinjau Dari Kemampuan Matematika Siswa Di Smpn 1 Semen. Simki-Techsain, 01(05), 12.

Farisdianto, D. D., \& Budiarto, M. T. (2014). Profil Kemampuan Spasial Siswa SMP dalam Menyelesaikan Masalah Geometri Ditinjau dari Perbedaan Kemampuan Matematika. Jurnal Ilmiah Pendidikan Matematika, 3(2), 77-84.

Febriana, E. (2015). Profil Kemampuan Spasial Siswa Menengah Pertama (SMP) dalam Menyelesaikan Masalah Geometri Dimensi Tiga Ditinjau dari Kemampuan Matematika. Jurnal Elemen, 1(1), 13. https://doi.org/10.29408/jel.v1i1.78

Guzel, N., \& Sener, E. (2009). High school students' spatial ability and 
Amalia Mareta Pungkasari, FX. Didik Purwosetiyono, Agnita Siska Pramasdyahsari Kemampuan Spasial Perception dalam Menyelesaikan Masalah Geometri Berdasarkan Teori Van Hiele Ditinjau dari Kemampuan Matematika

creativity in geometry. Procedia - Social and Behavioral Sciences, 1(1), 1763-1766. https://doi.org/10.1016/j.sbspro.2009.01.312

Ingri Y.M. Lalan, RullyCharitasIndra Prahmana, P. J. (2017). Penggunaan Alat Peraga Polydron Frameworks pada Materi Geometri Untuk Meningkatkan Kemampuan Spasial Matematis Siswa SMP Kelas VIII. IEEE International Conference on Acoustics, Speech, and Signal Processing (ICASSP) 2017, 41(2), 84-93.

Junsella Harmony, R. T. (2012). Pengaruh Kemampuan Spasial terhadap Hasil Belajar Matematika Siswa Kelas Vii SMP Negeri 9 Kota Jambi. 02(April), 11-19.

Ma'Rifatin, S., Amin, S. M., \& Siswono, T. Y. E. (2019). Students' mathematical ability and spatial reasoning in solving geometric problem. Journal of Physics: Conference Series, 1157(4). https://doi.org/10.1088/17426596/1157/4/042062

Muhassanah, N., Sujadi, I., \& Riyadi. (2014). Analisis Keterampilan Geometri Siswa Dalam Memecahkan Masalah Geometri Berdasarkan Tingkat Berpikir Van Hiele. Jurnal Elektronik Pembelajaran Matematika, 2(1), 54-66. Retrieved from http://jurnal.fkip.uns.ac.id

Musa, D., \& Aditya, L. (2014). Deskripsi Level Berpikir Geometri menurut Teori Van Hiele berdasarkan Kemampuan Geometri dan Perbedaan Gender pada Siswa Kelas VII SMP Negeri 8 Parepare. 4(2), 103-116.

Purwosetiyono, F. D. (2011). Implementasi Perangkat Pembelajaran Matematika Dengan Strategi Pikat Berbantuan Cd Pembelajaran Dan Lks Pada Materi Dimensi Tiga Siswa Kelas X. Aksioma, 2(1).

Syahputra, E. (2013). Peningkatan Kemampuan Spasial Siswa Melalui Penerapan Pembelajaran Matematika Realistik. Jurnal Cakrawala Pendidikan, 3(3), 353-364. https://doi.org/10.21831/cp.v3i3.1624

Tosto, M. G., Hanscombe, K. B., Haworth, C. M. A., Davis, O. S. P., Petrill, S. A., Dale, P. S., Kovas, Y. (2014). Why do spatial abilities predict mathematical performance? Developmental Science, 17(3), 462-470. https://doi.org/10.1111/desc.12138

Yanty Putri Nasution, E. (2017). Meningkatkan Kemampuan Spasial Siswa Melalui Pembelajaran Geometri Berbantuan Cabri 3D. M A T H L I N E: Jurnal Matematika Dan Pendidikan Matematika, 2(2), 179-194. https://doi.org/10.31943/mathline.v2i2.45 